\title{
UMA PROPOSTA PARA AVALIAR A SUSTENTABILIDADE DA EXPANSÃO DO CULTIVO DA CANA-DE-AÇÚCAR NO ESTADO DO MATO GROSSO DO SUL
}

\section{An approach to assess the sustainability for sugarcane expansion in Mato Grosso do Sul - Brazil}

\author{
Lucy Teixeira Guimarães \\ Engenheira Química, Dra. em Planejamento Ambiental \\ Coordenação de Recursos Naturais e Estudos Ambientais (CREN) - IBGE. \\ Rio de Janeiro/RJ - Brasil \\ lucy.guimaraes@ibge.gov.br \\ Ana Paula Dias Turetta \\ Geógrafa, Doutora em Ciência dos Solos - Pesquisadora da EMBRAPA Solos \\ Rio de Janeiro/RJ - Brasil \\ anaturetta@cnps.embrapa.br \\ Heitor Luiz da Costa Coutinho \\ Agrônomo, Doutor em Ciências Biológicas - Pesquisador da EMBRAPA Solos \\ Rio de Janeiro/RJ - Brasil \\ heitor@cnps.embrapa.br
}

Artigo recebido para publicação em 06/01/2010 e aceito para publicação em 14/05/2010

RESUMO: $\quad$ A busca pelo desenvolvimento sustentável tem impulsionado a substituição dos combustíveis fósseis pela utilização de combustíveis renováveis, o que tem possibilitado avanços na pesquisa agropecuária e industrial elevando mundialmente a competitividade do Brasil no setor sucroalcooleiro. A expansão da cultura da cana-de-açúcar e o desenvolvimento e modernização do setor sucroalcooleiro têm contribuído incontestavelmente para o fortalecimento do agronegócio brasileiro e, consequentemente, para o crescimento da economia do País. O território brasileiro com enormes áreas com potencial agrícola e o avanço tecnológico do setor da cana, têm incentivado o Governo Brasileiro no direcionamento dos planos governamentais de expansão da cultura da cana-de-açúcar em áreas de pastagens degradadas, principalmente na região centro-oeste do país. O presente artigo tem como objetivo apresentar resultados da aplicação de uma metodologia de avaliação da sustentabilidade frente a ampliação da cultura de cana-de-açúcar no Estado do Mato Grosso do Sul. Alguns indicadores de sustentabilidade foram selecionados para as microrregiões do Estado do Mato Grosso do Sul, que foram avaliadas quanto à sua sustentabilidade e comparadas através da metodologia do Barômetro de Sustentabilidade.

Palavras-chave: Indicadores de Sustentabilidade. Cana-de-açúcar. Barômetro de Sustentabilidade.

ABSTRACT: The necessity of sustainable development has driven the replacement of fossil fuels by using renewable sources, which has enabled advances in agricultural and industrial research and strengthened the competitiveness of the Brazilian's sugarcane industry. The sugarcane expansion and the development and modernization of the sugar sector are contributing to the strengthening of the Brazilian agribusiness 
and for brazilian's economic growth. The Brazilian territory has big areas with agricultural potential, and the technological advance in sugarcane industry has encouraged the Brazilian government to invest on the sugarcane expansion in degraded pastures, mainly in the central-western. This article aims to present results of the use of a methodology for assessing sustainability of the sugarcane expansion in Mato Grosso do Sul State. Some sustainability indicators were selected for the micro-region of Mato Grosso do Sul, which were evaluated for their sustainability and compared using the methodology of the Sustainability Barometer.

Keywords: Sustainability indicators. Sugarcane. Sustainability Barometer.

\section{INTRODUÇÃO}

Atualmente, acentuam-se as discussões sobre alternativas para a substituição dos combustíveis fósseis motivadas pelo aumento de demanda de energia e pela busca por opções com menor emissões de gases de efeito estufa tendo em vista a questão das mudanças climáticas.

Muitos países possuem uma vantagem compe- titiva na produção de biocombustíveis, enquanto outros são incapazes de satisfazer o seu próprio mercado a partir de fontes internas (FIGURA 1). Dessa forma, o aumento no comércio de biocombustíveis é promissor e nesse contexto o Brasil apresenta uma vantagem competitiva em relação aos demais países.

A valorização do etanol como combustível limpo tem aumentado a demanda pelo produto, fazendo com que haja uma projeção da expansão da cultura

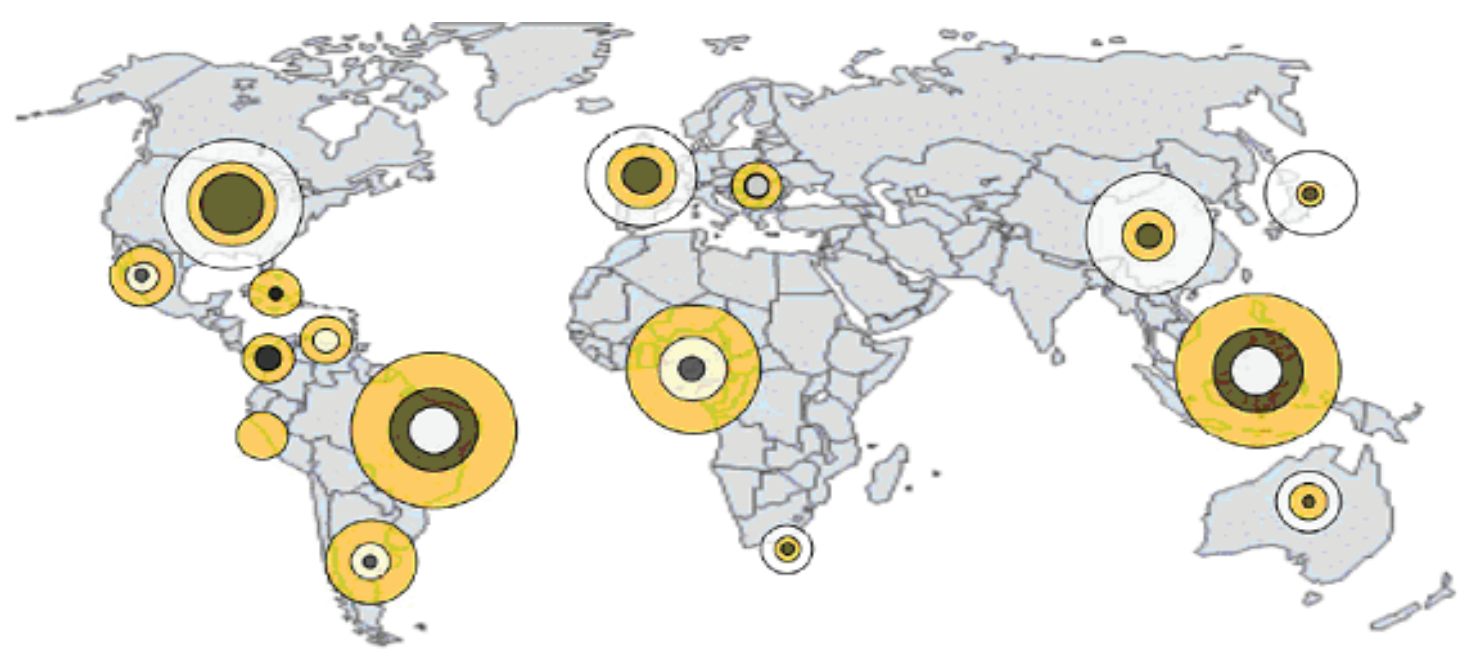

Feedstock potential based on land available for devotion to first generation biofuel feedstocks.

Theoretical biofuel demand, assessed to be $\sim 30 \%$ of liquid transport fuel consumption in 2006 .

- Biofuel production capacity in place at year end 2006.

(O) Feedstock potential exceeds biofuel demand and surplus production capacity - so export.

(3) Capacity less than biofuel demand so investment in infrastructure warranted to encourage export potential.

(9) Feedstock constrained and capacity less than demand - so import.

Source: New Energy Finance www.newenergyfinance.com

FIGURA 1: Indicação do potencial de produção de biocombustíveis de primeira geração, demanda teórica de biocombustíveis e capacidades de produção em vigor no final de 2006 em algumas regiões do globo. Fonte: New Energy Finance. 
da cana-de-açúcar, para os próximos anos, a fim de atender ao crescimento do mercado interno e suprir as exportações.

A demanda crescente por energias renováveis, a competitividade do álcool como combustível e a aceitação dos usuários pelos veículos movidos a álcool têm incentivado mais e mais a produção desse combustível. Assim o Brasil, detentor de vasta área territorial vem investindo no setor alcooleiro como forma de aproveitamento de áreas de pastagens degradadas.

Projeções realizadas pelo (MINISTÉRIO DA AGRICULTURA, PECUÁRIA E ABASTECIMENTO, 2008) indicam que o Brasil será, em pouco tempo, o principal pólo mundial de produção de biocombustíveis, feitos a partir de cana-de-açúcar e óleos vegetais, com destaque para a liderança na ocupação de novas áreas com cana-de-açúcar, cujo o aumento esperado é de cerca 66\% em área plantada até 2017. $\mathrm{Na}$ safra de 2007/08, a área cultivada com cana-deaçúcar aumentou 13\%, passando de 6,2 milhões para cerca de 7 milhões de hectares. Entre as safras 2005/2006 e 2006/2007 houve um aumento de cerca de $12 \%$ na área cultivada com cana-de-açúcar na região centro-sul, somente o Estado de São Paulo maior produtor nacional, cultivou cerca de 3,5 milhões de hectares (ACOMPANHAMENTO..., 2007).

No centro sul muitos estados vêm expandindo as áreas de produção de cana. Mato Grosso do Sul tem atraído empresários do setor, principalmente do Nordeste, pelo fato de possuir terras relativamente baratas (IBGE, 2003). No Estado de São Paulo, principal produtor nacional, a incorporação de novas áreas no oeste paulista é uma realidade, principalmente devido à disponibilidade de terras férteis, topografia adequada e logística para produção e escoamento da produção. Nota-se uma tendência da expansão da produção de cana em áreas antes ocupadas com a pecuária, atividade relativamente menos rentável frente ao valor da terra (ANSELMI, 2005). Stupiello (2005) comenta que a expansão da área de plantio da cana vem ocorrendo devido ao aumento da capacidade das unidades produtivas e a instalação de novas unidades. Com a expansão da cultura de cana-de-açúcar há uma forte tendência de valorização dos preços de terras em regiões próximas às usinas e, consequentemente, além da tendência da expansão da produção canavieira sobre as áreas de pastagens, pode ocorrer o deslocamento da produção de grãos, como a soja e o milho e de culturas permanentes, incluindo áreas de citricultura no oeste paulista.

O Estado de Mato Grosso do Sul aparece em destaque por estar localizado estrategicamente entre mercados potenciais como o MERCOSUL e grandes centros consumidores brasileiros. Além disso, seu potencial de recursos naturais e a infraestrutura moderna voltada para o apoio ao setor produtivo alavancam investimentos no desenvolvimento de atividades agroindustriais e de expansão do intercâmbio comercial.

A utilização de indicadores e índices para avaliação da sustentabilidade cresceu muito nas últimas décadas, por ser um instrumento que, de forma simples, expressa uma mensagem complexa, resultante de numerosos fatores. (HARDI,1997). Este tipo de ferramenta metodológica permite transmitir a informação técnica numa forma sintética, preservando o significado original dos dados, utilizando apenas as variáveis que melhor espelham os objetivos desejados. (SMEETS; WETERINGS, 1999). Os indicadores ambientais servem para diagnosticar alterações no estado do ambiente devido às atividades humanas; enquanto indicadores de desenvolvimento sustentável apresentam como foco a integridade dos recursos naturais, frente ao programa de crescimento/desenvolvimento econômico aplicado em unidades territoriais locais, regionais ou nacionais. (ALFARO; OYAGUE, 1997 apud RUFINO, 2002). A facilidade de comunicação é uma característica que confere aos indicadores de sustentabilidade a capacidade de expressar de forma simples, concisa e confiável e de melhorar a percepção dos diferentes atores sobre os principais impactos do desenvolvimento e sua ligação com os problemas oriundos da relação entre a sociedade e o meio ambiente. (SMEETS; WETERINGS, 1999).

O presente trabalho é parte de um amplo projeto cujo objetivo principal foi gerar uma ferramenta de auxílio à tomada de decisão considerando-se a expansão da cana-de-açúcar no Brasil. Especificamente em relação ao que será aqui apresentado objetivou-se testar uma metodologia de avaliação da sustentabilidade considerando-se as microrregiões do Estado do Mato Grosso do Sul em relação a indicadores selecionados 
frente à ampliação da plantação da cultura da canade-açúcar. Para tal, foram selecionados alguns indicadores de sustentabilidade que permitiram a comparação entre as microrregiões de MS.

\section{MATERIAIS E MÉTODOS}

\section{Área de Estudo}

O Estado do Mato Grosso do Sul tem uma superfície de $357.124,96 \mathrm{~km}^{2}$ e uma população de 2.265.274 habitantes (IBGE, 2007) distribuídos em
11 microrregiões e 77 municípios (FIGURA 2).

Mato Grosso do Sul está localizado na região Centro-Oeste e se encontra numa posição privilegiada, em função da proximidade dos grandes centros consumidores e distribuidores do País, onde se destacam as regiões Sul e Sudeste. Além disso, o Estado apresenta boa infraestrutura viária o que o qualifica como centro distribuidor.

Em relação à cultura de cana-de-açúcar, segundo o IBGE (2007), o Estado apresenta a seguinte situação (TABELA 1):
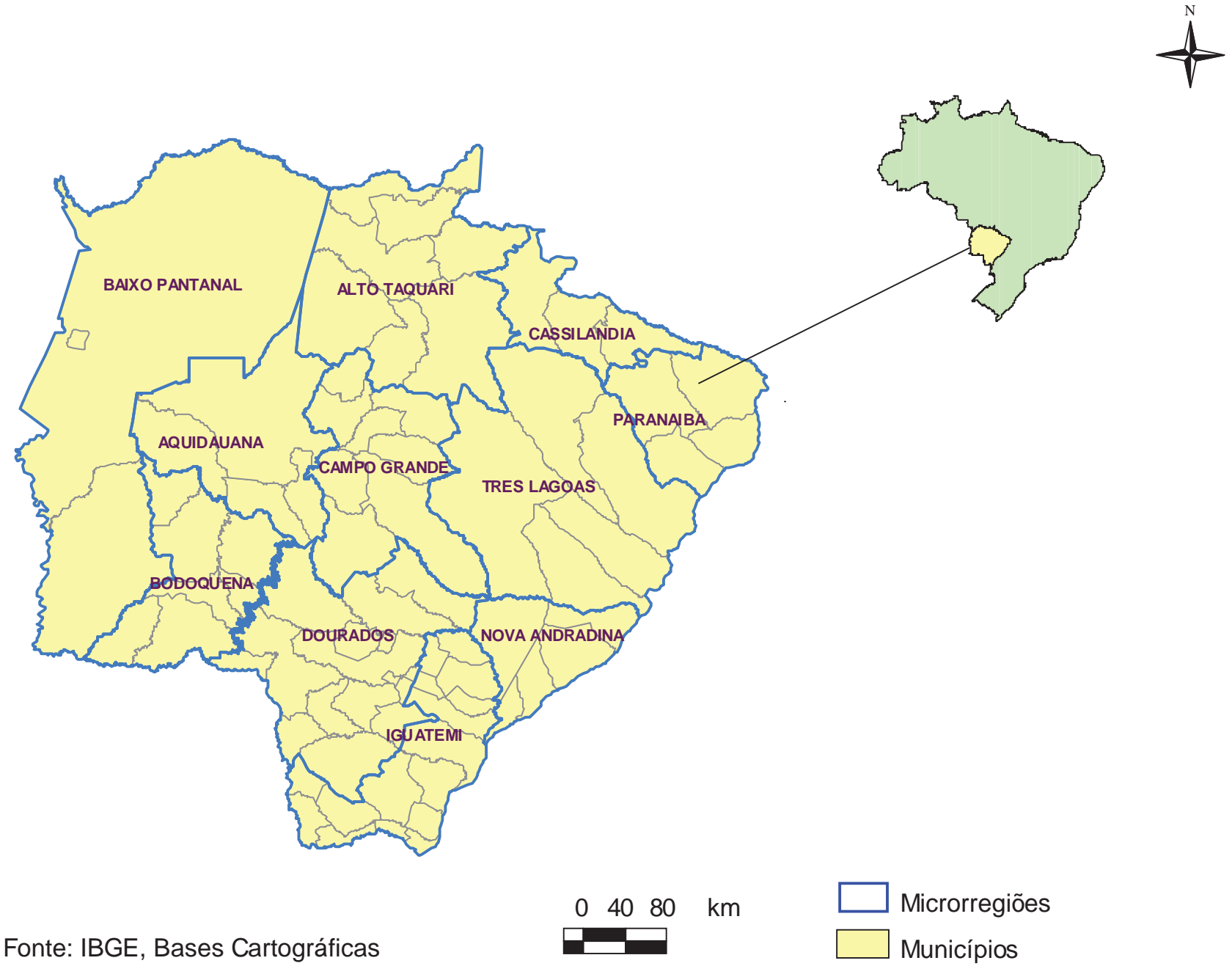

Fonte: IBGE, Bases Cartográficas

FIGURA 2: Estado do Mato Grosso do Sul e microrregiões. 
TABELA 1: Cana-de-açúcar: quantidade produzida, valor da produção, área plantada e colhida e rendimento médio (IBGE, 2007).

\begin{tabular}{lr}
\hline Quantidade produzida (Ton) & 15.839 .993 \\
Valor da produção (R\$) & 482.739 \\
Área plantada (ha) & 191.577 \\
Área colhida (ha) & 191.577 \\
Rendimento médio (Kg/ha) & 82.682 \\
\hline
\end{tabular}

\section{A análise por microrregiões}

As microrregiões são formadas por um grupo de municípios que corresponde ao menor nível administrativo no Brasil e foram definidas pelo IBGE na década de 1970 . O critério para se criar uma microrregião é baseado na união entre as características naturais, sociais e econômicas de municípios de um mesmo Estado (IBGE, 1970). Na década de 1990, o conceito de microrregião foi melhorado e passou a considerar algumas das peculiaridades relativas à organização do espaço (IBGE, 1997), incluindo a relação entre microrregiões em numerosos aspectos da estrutura de produção, agricultura, indústria, indústrias extrativas minerais e pesca.

Dessa forma, optou-se por trabalhar com o recorte de microrregiões considerando-se que as mesmas já caracterizam a agregação de situações socioeconômicas e naturais semelhantes.

\section{Seleção dos indicadores de sustentabilidade(IDS)}

Uma série de critérios foi utilizada para a seleção dos indicadores de sustentabilidade. $\mathrm{O}$ ponto inicial foi a checagem da lista de indicadores utilizados no projeto Sensor desenvolvido na Europa, o qual esse estudo está inserido, conforme pode ser visto em Monteiro et al. (2008). Os autores correlacionaram os indicadores de sustentabilidade utilizados na Europa com a disponibilidade dos mesmos em base de dados de instituições brasileiras e da América Latina, considerando a sua disponibilidade temporal e espacial. A partir dessa referência foram selecionados aqueles indicadores que eram mais sensíveis aos possíveis impactos da expansão da cana-de-açúcar e também com melhor disponibilidade de dados. Para essa seleção, considerou-se o critério da multidisciplinaridade e as três dimensões da sustentabilidade: ambiental, econômica e social. Em março de 2009 foi realizado um workshop do projeto Sensor no Rio de Janeiro onde vários especialistas em estudos de indicadores de sustentabilidade e do setor sucroalcooleiro estiveram presentes e foi possível debater sobre o setor e os indicadores selecionados. Os presentes consideraram que, para um primeira avaliação, esses indicadores estariam adequados e que seria uma importante contribuição ao amadurecimento de questões relativas aos estudos de sustentabilidade, considerando-se a expec-

\begin{tabular}{|c|c|c|}
\hline Dimensões & $\mathrm{N}^{\circ}$ de indicadores & Indicadores \\
\hline $\begin{array}{l}\text { Ambiental } \\
\text { Refere-se a informações sobre as condições e as mudanças nos recursos } \\
\text { naturais como solo e água. }\end{array}$ & 2 & $\begin{array}{l}\text { - } \quad \text { Consumo de Agrotóxicos } \\
\text { Domicílios atendidos por rede } \\
\text { geral de água }\end{array}$ \\
\hline $\begin{array}{l}\text { Social } \\
\text { Caracteriza-se por medidas referentes a condições de renda da população } \\
\text { com indicadores que contemplam de distribuição de renda e emprego. }\end{array}$ & 2 & $\begin{array}{l}\text { - Índice de Gini } \\
\text { Pessoal ocupado no setor } \\
\text { Agropecuário }\end{array}$ \\
\hline $\begin{array}{l}\text { Econômica } \\
\text { Caracteriza as condições da produção das microrregiões no processo de } \\
\text { desenvolvimento. }\end{array}$ & 2 & $\begin{array}{ll}\text { - } & \text { PIB per capita } \\
\text { - } & \text { Saldo da Balança Comercial }\end{array}$ \\
\hline
\end{tabular}

QUADRO 1: Estrutura organizacional dos IDS para microrregiões. 
tativa de expansão da cana-de-açúcar no Brasil nos próximos anos. Os indicadores de sustentabilidade selecionados encontram-se listados no QUADRO 1.
Os QUADROS 2, 3 a seguir apresentam a descrição e as fontes onde foram obtidos os indicadores.

\begin{tabular}{|c|c|}
\hline INDICADOR & DESCRIÇÃO \\
\hline $\begin{array}{l}\text { Consumo de agrotó- } \\
\text { xicos }\end{array}$ & $\begin{array}{l}\text { Agrotóxicos ou pesticidas são substâncias químicas utilizadas para destruir ou } \\
\text { controlar pragas em culturas agrícolas. Estão divididos em classes de herbicidas, } \\
\text { fungicidas, acaricidas, entre outros. Cada grupo apresenta um componente ativo } \\
\text { com grau de toxicidade e periculosidade específico, tanto para o meio ambiente } \\
\text { quanto para o ser humano. Esse indicador apresenta o total de toneladas de pesti- } \\
\text { cidas consumidos na microrregião em um determinado período. }\end{array}$ \\
\hline $\begin{array}{l}\text { Acesso a sistema de } \\
\text { abastecimento de } \\
\text { água }\end{array}$ & $\begin{array}{l}\text { Percentual de domicílios com acesso a abastecimento de água por rede geral. O } \\
\text { indicador se constitui na razão, em percentual, entre a população com acesso a } \\
\text { água por rede geral e o total da população em domicílios particulares permanentes. } \\
\text { Por conta da legislação brasileira, toda água fornecida à população por rede de } \\
\text { abastecimento geral tem de ser tratada e apresentar boa qualidade. }\end{array}$ \\
\hline $\begin{array}{l}\text { Índice de Gini da } \\
\text { distribuição do rendi- } \\
\text { mento }\end{array}$ & $\begin{array}{l}\text { Expressa o grau de concentração na distribuição do rendimento da população em um } \\
\text { determinado período. } \\
\text { O Índice de Gini é expresso por um valor que varia de } 0 \text { (zero), situação de perfeita } \\
\text { igualdade a } 1 \text { (um), situação de desigualdade máxima. }\end{array}$ \\
\hline $\begin{array}{l}\text { Pessoal ocupado na } \\
\text { agricultura, pecuária, } \\
\text { silvicultura e explora- } \\
\text { ção florestal }\end{array}$ & Percentual de pessoas ocupadas, nos diversos setores econômicos. \\
\hline PIB per capita & $\begin{array}{l}\text { O Produto Interno Bruto per capita indica a renda média da população em um país } \\
\text { ou território. } \\
\text { As variáveis utilizadas para a construção deste indicador são o Produto Interno } \\
\text { Bruto - PIB, a preços constantes, e a população residente estimada para } 1^{\circ} \text { de } \\
\text { julho. } \\
\text { O indicador expressa a razão entre o PIB e a população residente. } \\
\text { O Produto Interno Bruto per capita é normalmente utilizado como um indicador } \\
\text { do ritmo de crescimento econômico do território analisado. }\end{array}$ \\
\hline Balança comercial & $\begin{array}{l}\text { Apresenta o saldo entre as exportações e as importações de bens de um determi- } \\
\text { nado território, em um determinado período. Seu valor é expresso em U\$ FOB. }\end{array}$ \\
\hline
\end{tabular}

QUADRO 2: Descrição dos indicadores. 
Uma proposta para avaliar a sustentabilidade da expansão do cultivo da cana-de-açúcar no Estado do Mato Grosso do Sul Lucy Teixeira Guimarães, Ana Paula Dias Turetta, Heitor Luiz Costa Coutinho

\begin{tabular}{|c|c|c|c|}
\hline INDICADOR & FONTE & COBERTURA & ANO \\
\hline Consumo de agrotóxicos & $\begin{array}{l}\text { IBGE - Indicadores de Desenvol- } \\
\text { vimento Sustentável } \\
\text { IBAMA }\end{array}$ & UF & 2000 a 2005 \\
\hline $\begin{array}{l}\text { Acesso a sistema de abas- } \\
\text { tecimento de água }\end{array}$ & IBGE - Censo demográfico & Município & 2000 \\
\hline $\begin{array}{l}\text { Índice de Gini da distri- } \\
\text { buição do rendimento }\end{array}$ & $\begin{array}{l}\text { Atlas do Desenvolvimento Huma- } \\
\text { no-PNUD }\end{array}$ & Município & 1991,2000 \\
\hline Pessoal ocupado & $\begin{array}{l}\text { IBGE - Cadastro Central de } \\
\text { Empresas }\end{array}$ & Município & 1996 a 2006 \\
\hline PIB per capita & $\begin{array}{l}\text { IBGE - Censo demográfico } \\
\text { IBGE - Produto Interno Bruto } \\
\text { dos Municípios } \\
\text { IBGE - Estimativa de População }\end{array}$ & Município & 2000 a 2006 \\
\hline Balança comercial & $\begin{array}{l}\text { Ministério do Desenvolvimento } \\
\text { Indústria e Comércio Exterior, } \\
\text { Secex }\end{array}$ & Município & 2000 a 2006 \\
\hline
\end{tabular}

QUADRO 3: Indicadores e fonte dos dados.

\section{RESULTADOS E DISCUSSÕES}

\section{Obtenção dos dados}

A análise documental das fontes pesquisadas revelou que o maior problema para a confecção de indicadores é a disponibilidade de dados confiáveis, sistematizados, apurados periodicamente, pesquisados de forma desagregada na base territorial, e de bancos de dados compatíveis. Normalmente em pesquisas oficiais, a menor desagregação disponível se dá na base territorial de município.

Também ficou caracterizado que dados econômicos e sociais são mais abundantes e fáceis de se conseguir do que dados ambientais. Em geral, os dados ambientais são pesquisados pelos órgãos municipais de fiscalização e controle e encontram-se em banco de dados próprios. Alguns indicadores têm dados pesquisados por projetos específicos ou trabalhos acadêmicos, mas esses dados não estão disponibili- zados de forma em nenhuma base, encontram-se disseminados por diferentes instituições e em diferentes mídias.

No Brasil, os órgãos ambientais estaduais de fiscalização e controle têm diferentes atuações no país. Alguns estados produzem e pesquisam dados de qualidade da água e do ar, mas na maioria dos estados brasileiros, esses órgãos ainda não dispõem de infraestrutura para gerar dados ambientais sistematizados.

Regras de decisão - elaboração dos escores para padronização dos indicadores

Para a avaliação da sustentaridade das microrregiões foi utilizada a metodologia do Barômetro de Sustentabilidade desenvolvido pelo The World Conservation Union, IUCN e o The International Development Research Centre, IDRC.

O Barômetro é uma ferramenta que trabalha as questões relativas ao desenvolvimento sustentá- 
vel, em qualquer nível do sistema, do local ao global, destinando-se às agências governamentais e não governamentais, aos tomadores de decisão e às pessoas envolvidas com o assunto. (PRESCOTT ALLEN, 1997 apud BELLEN, 2005).

Para a utilização do Barômetro, deve-se estar atento a algumas questões. A primeira é a necessidade de normalizar os valores dos indicadores (TABELA 2), que é feito da seguinte forma:

(a) cálculo da relação entre o limite superior menos o limite inferior do indicador e limite superior menos o limite inferior do barômetro, considerando-se a faixa onde o valor do indicador encontra-se;

(b) cálculo da relação entre o valor do indicador menos o limite inferior do indicador e o valor obtido em (a);

(c) o resultado obtido em (b) deve ser somado ao limite inferior da escala do barômetro onde $o$ valor do indicador encontra-se.

TABELA 2: Valores normalizados utilizando-se a escala do Barômetro de Sustentabilidade.

\begin{tabular}{|c|c|c|c|c|c|c|c|}
\hline Microrregiões & $\begin{array}{c}\text { Consumo } \\
\text { Agrotóxicos }\end{array}$ & $\begin{array}{l}\text { Acesso } \\
\text { água }\end{array}$ & $\begin{array}{l}\text { Índice } \\
\text { de Gini }\end{array}$ & $\begin{array}{c}\text { Pessoal } \\
\text { ocupado }(\%)\end{array}$ & $\begin{array}{c}\text { Pib per } \\
\text { capita }\end{array}$ & $\begin{array}{c}\text { Balança } \\
\text { comercial }\end{array}$ & $\begin{array}{l}\text { Nota } \\
\text { final }\end{array}$ \\
\hline Alto Taquari & 64 & 38 & 33 & 51 & 56 & 29 & 45 \\
\hline Aquidauana & 88 & 23 & 29 & 32 & 41 & 21 & 39 \\
\hline Baixo Pantanal & 100 & 48 & 33 & 13 & 68 & 0 & 44 \\
\hline Bodoquena & 99 & 19 & 31 & 21 & 42 & 25 & 39 \\
\hline Campo Grande & 68 & 49 & 36 & 6 & 52 & 27 & 40 \\
\hline Cassillândia & 100 & 38 & 30 & 45 & 85 & 26 & 54 \\
\hline Dourados & 40 & 38 & 33 & 32 & 53 & 28 & 37 \\
\hline Iguatemi & 40 & 18 & 37 & 26 & 45 & 25 & 32 \\
\hline Nova Andradina & 62 & 37 & 39 & 26 & 41 & 0 & 34 \\
\hline Paranaíba & 57 & 16 & 35 & 21 & 51 & 23 & 34 \\
\hline Três Lagoas & 58 & 31 & 37 & 61 & 68 & 0 & 42 \\
\hline
\end{tabular}

Outra questão é a definição dos limites de sustentabilidade de cada indicador, que deve ser estabelecido pelo usuário. Para minimizar a subjetividade no estabelecimento desses limites, optou-se por utilizar valores baseados em trabalhos publicados ou em critérios ou metas definidas como sustentáveis por instituições de pesquisa, a saber:

- Consumo de agrotóxicos - Dados de consumo de agrotóxicos só estão disponíveis espacialmente em nível de unidade de federação (UF), Mato Grosso do Sul, para os anos de 2000 a 2005, e não têm especificado o consumo por cultura. Para contornar esta situação, foi utilizado, como regra de decisão a área de cultura temporária plantada, considerando-se a cana-de-açúcar como cultura a ser expandida. Foi assumido o ano de 2006 como referência para avaliação do percentual de área plantada de cana. Considerouse uma expansão da cana sobre a área de pastagens e áreas de terras produtivas não utilizadas. Como o total de área plantada no Estado do Mato Grosso do Sul, totalizou em 20063.009 .887 ha, 1\% desse valor foi assumido como limite mínimo para criar a regra de decisão, considerando-se 2.118 ha de área plantada como sem importância para o impacto do consumo de agrotóxico, menor área plantada de cana neste ano, pertencente à microrregião do Baixo Pantanal. Levando-se em consideração que o total das áreas possíveis para expansão podem chegar até um valor maior que 22.000.000 ha no Estado, o limite superior da regra de decisão foi estipulado como 152.747 ha, valor total da área plantada de cana no ano de 2006.

As faixas delimitadas para uso no barômetro de sustentabilidade consideraram uma expansão máxima para a cana-de-açúcar tomando como referência a microrregião de Cassilândia, que no ano de 1996 apresentava, segundo o Censo Agropecuário do IBGE, 
uma área total de 836.110 ha em áreas de pastagem e terras produtivas não utilizadas, sendo esse o menor valor entre as microrregiões avaliadas. Esse valor foi adotado por ser o último valor disponível, já que os dados do Censo Agropecuário 2008 ainda não estão disponíveis.

- Domicílios com acesso a rede geral de água (\%) - a Meta 7 dos Objetivos do Milênio é garantir a sustentabilidade ambiental, reduzindo pela metade, até o ano de 2020, a população sem acesso à água potável. Foi fixado neste trabalho um limite superior para $95 \%$ ou mais de domicílios atendidos com água na rede geral, e como limite mínimo sustentável 70\% de atendimento.

- Índice de Gini - 0,5 é considerado um valor que representa fortes desigualdades na distribuição de renda (IBGE, 2004). Como esse indicador é considerado um indicador negativo, ou seja, quanto maior o valor pior é sua sustentabilidade, o limite superior considerado de importância foi para valores maiores ou iguais a 0,5 , estabelecendo-se a faixa entre $0,2 \mathrm{e}$ 0,5 para alguma importância e abaixo de 0,2 como limite inferior sem importância.

- Pessoal ocupado - Considerando-se o ano de 2006 como referência, a microrregião de Alto Taquari foi a que apresentou o maior percentual de pessoal ocupado no setor de agricultura, pecuária, silvicultura e exploração florestal, totalizando $16 \%$ de pessoal ocupado. Como a média do Estado do Mato Grosso do Sul foi de 3\% de pessoal ocupado nesse setor, o limite de $16 \%$ ou mais foi assumido como sem importância, entre $6 \%$ e $16 \%$ como faixa de alguma importância e abaixo de $6 \%$ como importante. Para a construção das faixas do barômetro, o limite de 34\% foi assumido considerando-se essa participação para o Estado de São Paulo, nos empregos formais nos setores de cana e açúcar.

- PIB per capita - Os limites foram assumidos, considerando-se que os países com PIB per capita inferior a US\$ 2.000 (África Subsaariana) apresentam baixo índice de desenvolvimento humano (nível insustentável na escala do barômetro) e os países com PIB per capita superior a US\$ 40.000 (países escandinavos e Estados Unidos) apresentam alto índice de desenvolvimento humano, segundo o PNUD (2002) (sustentável). Os países com PIB per capita entre US\$
6.000 e 12.000 (países emergentes do sudeste da Ásia e América Latina) foram classificados como intermediários. Considerando-se para o ano de 2006 o valor do dólar fiscal de R $\$$ R $\$ 2,136$, temos: limite inferior $\mathrm{R} \$ 4.272,00$, e limite superior R\$ 85.440,00. (KRONEMBERGER et al., 2008)

- Balança Comercial - Definido pelos autores, considerando que para países com alto grau de endividamento externo, a geração de saldos comerciais é essencial para o pagamento dos compromissos externos. Assim, saldos negativos são considerados insustentáveis, enquanto a sustentabilidade é alcançada quando o saldo da balança comercial é superior a $10 \%$ do PIB. (KRONEMBERGER et al., 2008)

Para a avaliação da sustentabilidade das microrregiões utilizando-se os critérios adotados acima foram utilizados os dados obtidos do ano de 2006, quando possível. (vide QUADRO 3, que apresenta os indicadores com sua disponibilidade temporal). Para os indicadores que não têm dados disponíveis nesse ano, foram utilizados dados do último ano disponível.

A escala utilizada no BS para cada um dos eixos, varia de 0 a 100 , consistindo em 100 pontos e uma base 0 . Ela está dividida em cinco setores de 20 pontos cada com a seguinte classificação:

0-20 ruim / insustentável;

21-40 pobre / potencialmente insustentável;

41-60 médio / intermediário;

61-80 bom / potencialmente sustentável;

81-100 muito bom / sustentável.

A TABELA 3 apresenta os resultados normalizados para as microrregiões do Estado do Mato Grosso do Sul, utilizando-se as escalas definidas para os indicadores, para uso do barômetro de sustentabilidade.

A TABELA 4 apresenta a classificação final das microrregiões segundo o Barômetro de Sustentabilidade e a FIGURA 3 apresenta esses valores espacializados por microrregião do Mato Grosso do Sul. 


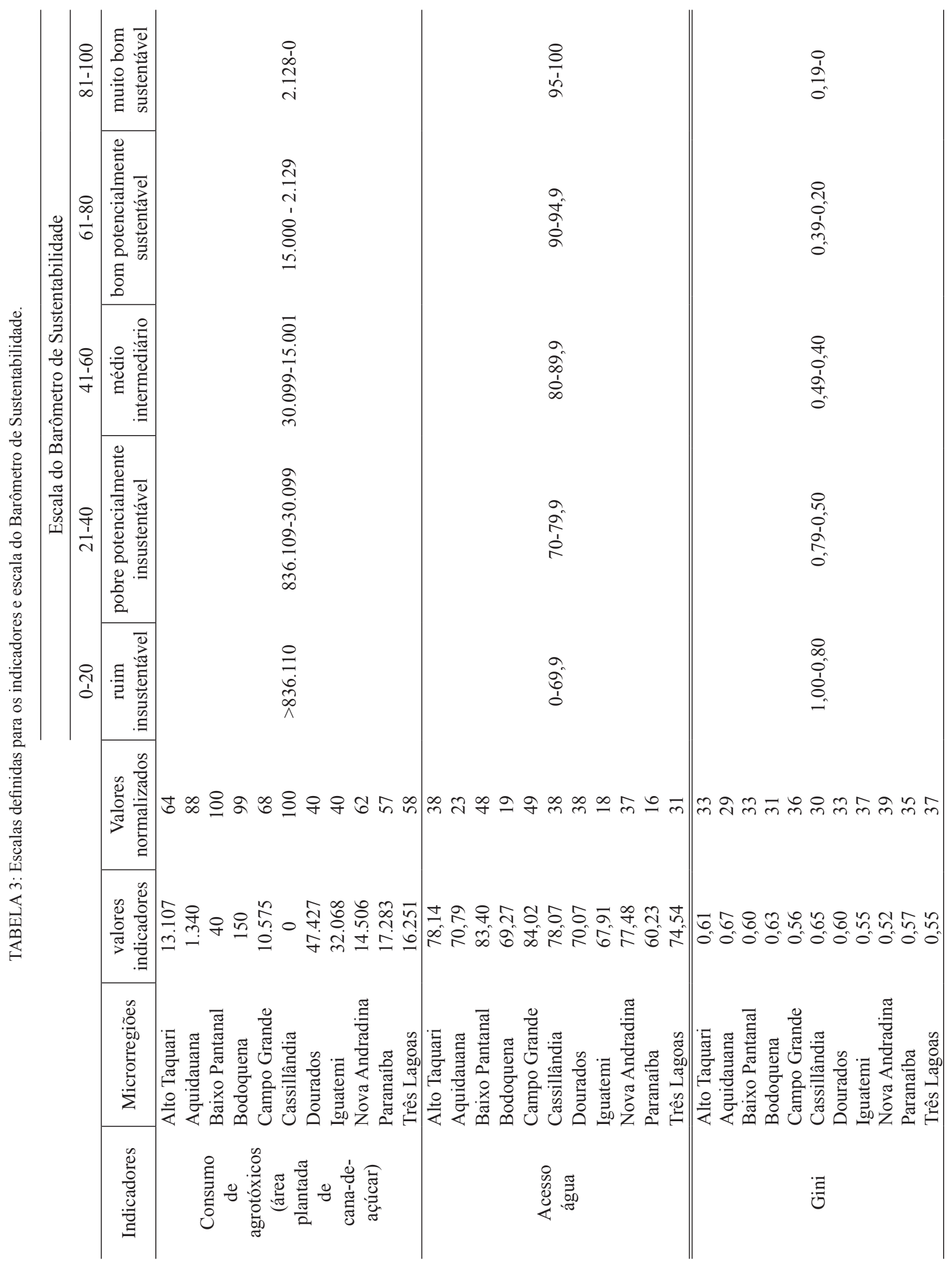

Sociedade \& Natureza, U berlândia, 22 (2): 313-327, ago. 2010 


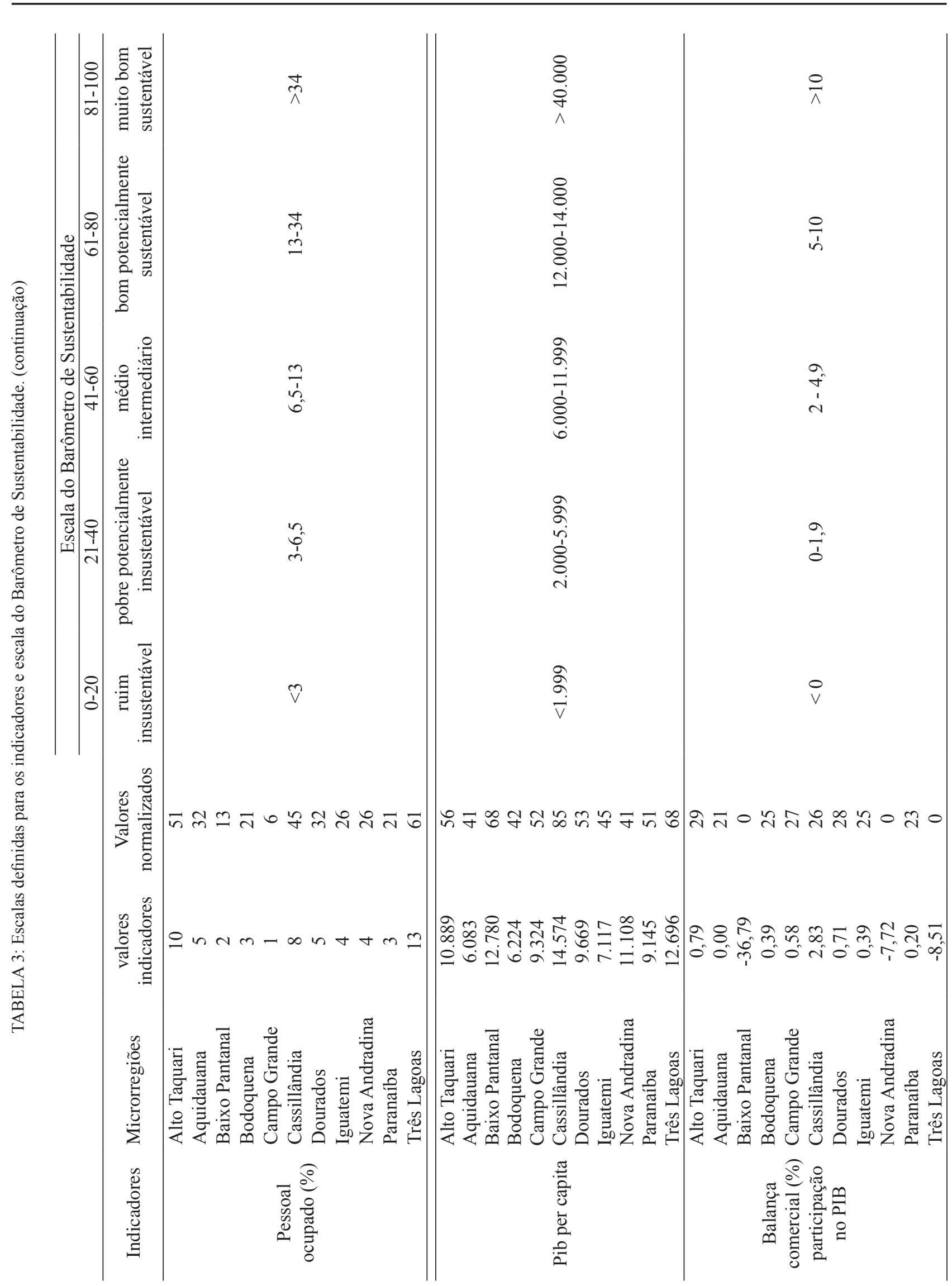


Uma proposta para avaliar a sustentabilidade da expansão do cultivo da cana-de-açúcar no Estado do Mato Grosso do Sul Lucy Teixeira Guimarães, Ana Paula Dias Turetta, Heitor Luiz Costa Coutinho

TABELA 4: Classificação final das microrregiões segundo o Barômetro de Sustentabilidade.

\begin{tabular}{lcl}
\hline Microrregiões & Nota final & Classificação do Barômetro \\
\hline Cassillândia & 54 & médio / intermediário \\
Alto Taquari & 45 & médio / intermediário \\
Baixo Pantanal & 44 & médio / intermediário \\
Três Lagoas & 42 & médio / intermediário \\
Campo Grande & 40 & pobre / potencialmente insustentável \\
Bodoquena & 39 & pobre / potencialmente insustentável \\
Aquidauana & 39 & pobre / potencialmente insustentável \\
Dourados & 37 & pobre / potencialmente insustentável \\
Nova Andradina & 34 & pobre / potencialmente insustentável \\
Paranaíba & 34 & pobre / potencialmente insustentável \\
Iguatemi & 32 & pobre / potencialmente insustentável \\
\hline
\end{tabular}

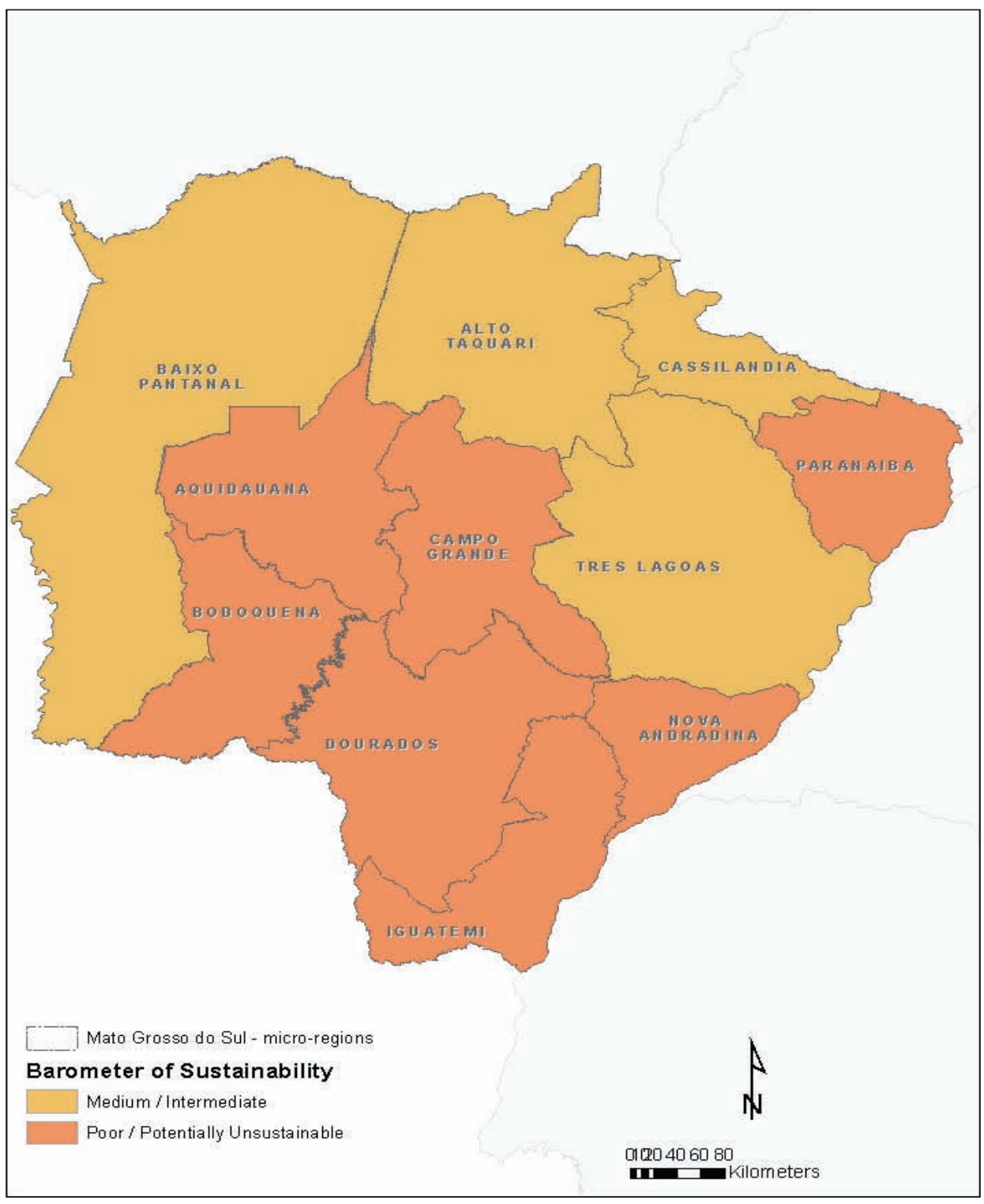

FIGURA 3: Microrregiões do Estado do MS e sua sustentabilidade de acordo com a escala do Barômetro de Sustentabilidade. 
Os resultados da TABELA 4 e FIGURA 3 mostram que apenas quatro microrregiões do Estado do Mato Grosso do Sul - Baixo Pantanal, Alto Taquari, Três Lagoas e Cassilândia - estariam na categoria "Média/Intermediária" de sustentabilidade, considerando-se a expansão da cana-de-açúcar nesse Estado. Essas regiões coincidem também com aquelas que não tiveram aumento na área plantada com cana-deaçúcar no período de 1990 a 2007, conforme pode ser observado no gráfico da FIGURA 4. Essas microrregiões também são aquelas onde está localizado o Pantanal e que por esse motivo possuem legislação restritiva à expansão da cana-de-açúcar.

Também é possível observar nas FIGURAS 3

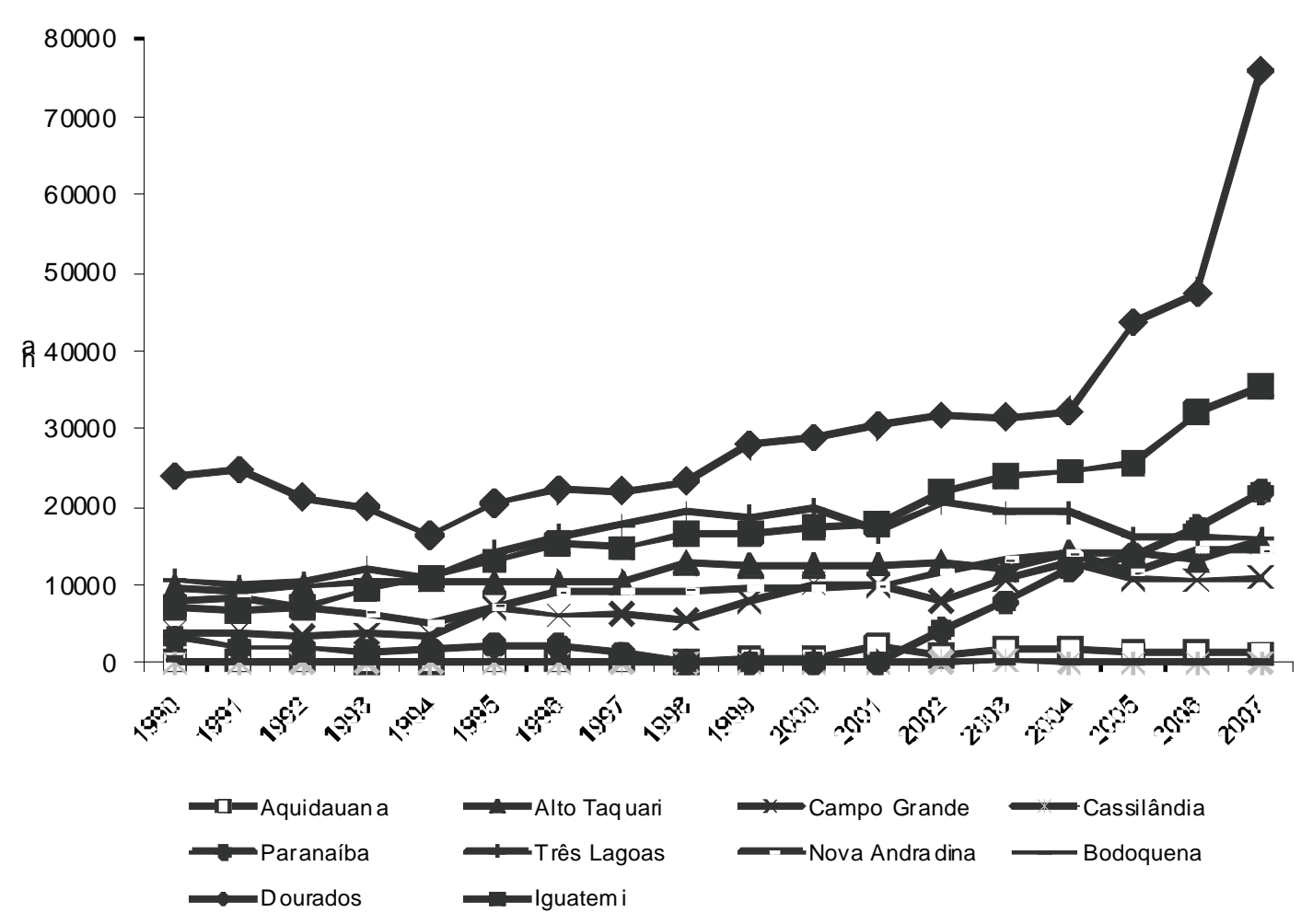

FIGURA 4: Área plantada com cana-de-açúcar entre 1990 e 2007 nas microrregiões do Estado do Mato Grosso do Sul. Fonte: PAM - IBGE. (2009).

e 4 que apesar dessa restrição em algumas microrregiões, nas demais que não possuem esse tipo de controle, a cana-de-açúcar apresenta um expressivo aumento em área, principalmente naquelas localizadas no limite do Estado de São Paulo, principal produtor de cana-de-açúcar do país.

Os dados sugerem a necessidade de medidas de controle da atividade no estado para que a expansão da cultura da cana possa trazer melhorias para a população que se reflitam nos valores dos indicadores. A identificação e seleção de indicadores de sustentabilidade poderão contribuir para uma avaliação ex-ante dos impactos ambientais da expansão do agronegócio em diferentes cenários resultantes da implementação de políticas públicas de mudança de uso do solo. Esses resultados podem direcionar a formulação de políticas públicas que levem a sustentabilidade dessa atividade no país.

O governo brasileiro demonstra preocupação no ordenamento da atividade canavieira no país e realizou o zoneamento agroecológico da cana-de-açúcar que incorpora aspectos ambientais, edafoclimáticos e de uso do solo. Espera-se que a produção da cana-deaçúcar siga as indicações das legislações ambientais 
Uma proposta para avaliar a sustentabilidade da expansão do cultivo da cana-de-açúcar no Estado do Mato Grosso do Sul Lucy Teixeira Guimarães, Ana Paula Dias Turetta, Heitor Luiz Costa Coutinho

- federais e estaduais - e que seu plantio seja feito de maneira a evitar a competição em áreas de produção de grãos e em áreas com restrições ambientais e antrópicas (bioma Amazônico, Pantanal, áreas de proteção, áreas indígenas, etc.).

\section{CONSIDERAÇÕES FINAIS}

- A disponibilidade espacial e temporal dos indicadores de sustentabilidade demonstrou ser um dos maiores obstáculos para a realização de estudos para análise de sustentabilidade no Brasil.

- Foi observada maior disponibilidade de indicadores sociais e econômicos do que de indicadores ambientais. Observou-se que os indicadores sociais e econômicos encontram-se organizados e disponibilizados em base de dados o que os torna mais acessíveis que os ambientais. Esses, além de apresentarem menor disponibilidade espacial e temporal, encontram-se dispersos em publicações em diferentes instituições de pesquisas e em diferentes mídias.

- Por não haver indicadores específicos para o setor sucroalcoleiro foi necessário uma série de inferências para a realização desse estudo. A consulta a especialistas do setor foi de grande relevância para a escolha final dos indicadores a serem trabalhados.

- As regras de decisão demonstram ser uma boa alternativa para contornar a escassez de informação específica sobre limiares de sustentabilidade.

- O Barômetro da Sustentabilidade demonstrou ser uma ferramenta robusta, capaz de satisfazer a proposta de avaliar a sustentabilidade.

- Para melhor compreensão do comportamento das microrregiões em relação à sustentabilidade, sugere-se o acompanhamento com indicadores e uso do Barômetro de Sustentabilidade, pela facilidade de uso e aceitação de diferentes tipos de indicadores.

- O presente estudo se propôs a testar uma metodologia de avaliação da sustentabilidade, tendo sido indicadas questões importantes a serem consideradas em estudos dessa natureza. No entanto, outros estudos são necessários, considerando-se também outros indicadores de sustentabilidade, para uma avaliação mais detalhada da sustentabilidade da expansão da canade-açúcar no estado do Mato Grosso do Sul.

\section{REFERÊNCIAS}

ÁLCOOL: etanol brasileiro. Disponível em: <http:// www.biodieselbr.com/energia/alcool/etanol.htm>. Acesso em: 10 jun. 2009

ACOMPANHAMENTO da Safra Brasileira: Canade-açúcar. Brasília, DF: CONAB, 2007. Disponível em: <www.conab.gov.br>. Acesso em: 09 ago. 2009.

ANSELMI, R. De 40 novas usinas, 30 serão no oeste paulista. Jornal Cana. Campinas, fev. 2005. Disponível em <http://www.jornalcana.com.br/pdf/134/FEICANA05.pdf $>$. Acesso em: 09 ago. 2009.

BELLEN, H. M. van. Indicadores de Sustentabilidade: uma análise comparativa. Rio de Janeiro: FGV Editora, 2005.

HARDI, P. Measuring sustainable development: review of current practice. Occasional Paper, n. 17, nov. 1997.

IBGE. Divisao do Brasil em Microregiones Homogeneas. Rio de Janeiro, RJ: IBGE, 1970.

RJ: IBGE, 1997.

Divisão territorial do Brasil. Rio de Janeiro, Indicadores de Desenvolvimento Sustentável, Brasil. Rio de Janeiro, RJ: IBGE, 2004.

Levantamento Sistemático da Produção Agrícola, Rio de Janeiro, v.15, n.12, p. 84, 2003. Disponível em: <www.ibge.gov.br>. Acesso em: 09 ago. 2009.

Pesquisa Agrícola Municípal. Rio de Janeiro, RJ: IBGE, 2007. Disponível em: <www.sidra. ibge.gov.br/bda/PAM>. Acesso em: 09 de ago. 2009.

KRONEMBERGER, D. M. P.; CLEVELARIO JUNIOR, J.; NASCIMENTO, J. A. S do.; COLLARES, J. E. R.; SILVA, L. C. D. da. Desenvolvimento sustentável no Brasil: uma análise a partir da aplicação do "barômetro de sustentabilidade". Sociedade e $\mathrm{Na}$ -

Sociedade \& N atureza, U berlândia, 22 (2): 313-327, ago. 2010 
tureza, Uberlândia, v. 20, n.1, jun. 2008. doi: 10.1590/

S1982-45132008000100002

MINISTÉRIO DA AGRICULTURA, PECUÁRIA E ABASTECIMENTO. Assessoria de gestão estratégica. Projeções do Agronegócio Mundial e Brasil 2006/07 a 2017/18. Brasília, DF: MAPA, 2008.

MONTEIRO, J. M.; VEIGA, L. B. E.; COUTINHO, H. L. C. Indicadores de desenvolvimento sustentável para avaliação de impactos associados à expansão da cana-de-açúcar para a produção de biocombustíveis: uma análise baseada nos indicadores de desenvolvimento sustentável da União Européia. In: MALHEIROS, T. F.; PHILIPPI JUNIOR, A.; COUTINHO, S. M. V. Governança ambiental e indicadores de sustentabilidade: resultados do II workshop internacional de pesquisade em indicadores de sustentabilidade - WIPIS 2008. São Carlos: EESC/USP, 2008.

PNUD. Relatório de Desenvolvimento Humano 2002. Nova Iorque. Oxford University Press. 2002.

RUFINO R. C. Avaliação da qualidade ambiental do município de tubarão (SC) através do uso de indicadores ambientais. 2002. 113 f. Dissertação (Mestrado em Engenharia de Produção) - Universidade Federal de Santa Catarina, Florianópolis, 2002.

SMEETS E.; WETERINGS R. Environmental indicators: Typology and overview. EEA Technical report, Copenhagen, n. 25, 1999.

STUPIELLO, J. P. A expansão canavieira no Brasil. In: II SIMPÓSIO DE TECNOLOGIA DE PRODUÇÃO DE CANA-DE-AÇUCAR, 2005, Piracicaba, SP. Anais... Piracicaba: Unipress Disc Records do Brasil, 2005. 1 CD-ROM. 